\title{
Comentarios
}

\section{Sobre la elección del gabinete}

Las elecciones presidenciales de este año fueron una muestra de a lo que puede llegar ARENA con el fin de permanecer en el poder. Para un observador extemo era impensable que el partido de hace tan sólo dos años pudiera impulsar la candidatura de una persona como Francisco Flores y seguirle el juego en el tono conciliador y sosegado que le pretendió imprimir a la campaña. También era impensable que al que en ese momento era la cabeza visible de un partido tan reacio a reconocer críticas y a realizar balances de sus propios errores, se le permitiera disentir en puntos importantes de los gobiernos que le habían precedido y aceptar que ciertos problemas fundamentales de la realidad salvadoreña aún no habían sido resueltos.

La dinámica que alimentó este proceso no fue, como algunos ingenuos y los publicistas del partido pretendieron hacerlo ver, una voluntad de cambio, sino más bien una voluntad de poder, al menos desde una perspectiva institucional. En otras palabras, a la institución no le importaba promover a un Francisco Flores tan en apariencia desmarcado de las actitudes y aptitudes tradicionales del partido, si con ello garantizaba por cinco años más el control del Estado. De ello que fuera absurdo preguntarse si Flores podría insuflar su talante moderado hacia el interior de las filas del partido, caracterizado desde siempre por su intolerancia.

Sólo si se hubiera verificado un cambio generacional en el interior del partido se podría sustentar la hipótesis de que Flores representaría un viraje en la forma de hacer política de ARENA. Un cambio generacional que no se limitara a un simple relevo de los cuadros viejos por otros más jóvenes, sino a un cambio de mentalidad y actitudes. $Y$ de esto, obviamente, no hay signo en el partido de de- recha. Basta observar cómo los compañeros generacionales de Flores (René Figueroa o Walter Araujo, por ejemplo) son calcos exactos del cinismo, la intolerancia y la despreocupación social de sus mayores. Así, entre un joven líder arenero y Acosta Oertel no es posible apreciar mayor diferencia que un número de años.

La otra pregunta importante que se planteó durante la campaña electoral era si a Francisco Flores su partido le permitiría llevar adelante una gestión gubernamental diferente. Con ello se aceptaba que Flores era una excepción y que esta característica le terminaría implicando permanentes choques con las autoridades del partido y los funcionarios areneros. Teniendo en cuenta lo que hemos dicho antes, la respuesta a esta interrogante se encontraría en los beneficios que la gestión de Flores le proporcione a ARENA. Así, en la medida en que a la institución le sea útil y considere que aleja con ello la posibilidad de verse relevada del poder, a Flores se le permitirá llevar a caba el gobierno sui generis que ha prometido. En caso contrario, en el caso de que ARENA se sintiera de nuevo segura de su posición en el espectro político, cabría esperar un gobierno similar al de Calderón Sol y Cristiani, en el que Flores se vería obligado - supongamos por un momento que de verdad le interese ser diferente políticamente - a plegarse a las necesidades y exigencias más propias de ARENA y los sectores que representa.

Plantearse con realismo la cuestión es útil de cara a la cercana toma de posesión de Flores y Quintanilla; especialmente si se pretende evaluar con seriedad una de las medidas que el primero pretende llevar a cabo una vez esté sentado en la silla presidencial: reformar la modalidad de elec- 


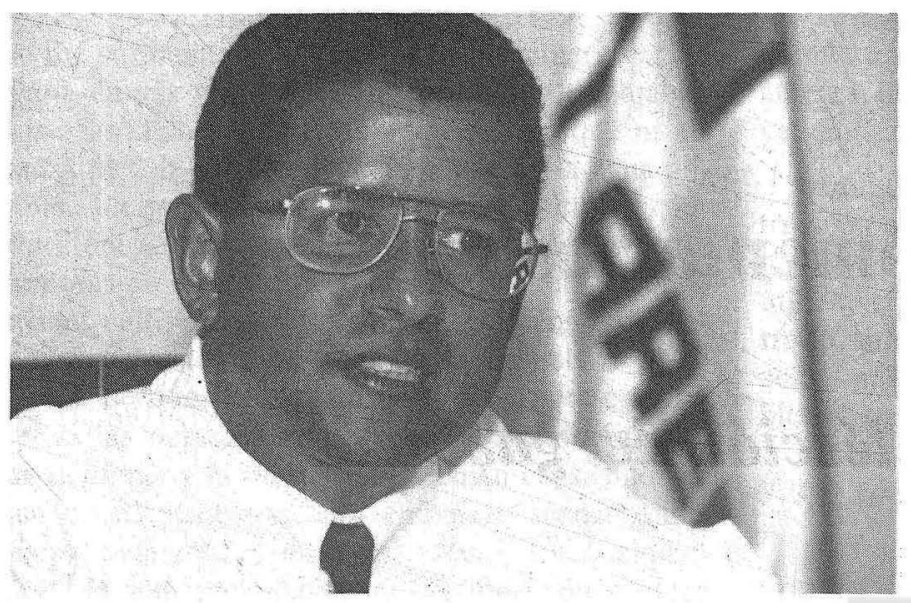

mo la elección de los próximos ministros, de la cual dependerá en buena parte la eficiencia y transparencia de sus gestiones, el gesto de Flores sería trascendental y marcaría la pauta de lo que sería su labor en el lustro venidero.

Ahora bien, desde la voluntad de poder de ARENA, las declaraciones de Flores sobre el gabinete serían signo de que para el partido de derecha la campaña electoral no ha concluido todavía y de que no concluirá hasta que en las elecciones de diputados y alcaldes se alcance el lugar que se perdió en 1997. Es decir, ARENA, como lo hizo en la campaña electoral pasada, estaría utilizando

ción del gabinete. Como nueva manifestación de lo desconcertante y sorpresiva que es su figura, Flores anunció, poco después de que fuera segura su victoria en las elecciones, que el proceso de conformación de su gabinete se pondría en manos de una Comisión de Notables que evaluaría la idoneidad y capacidad de los candidatos a ocupar los cargos, para los cuales incluso podrían aplicar figuras ajenas al partido. Además, Flores declaraba en forma tajante que los nuevos ministros estarían supervisados de manera constante y tendrían que dar cuenta públicamente de sus actos.

Aparentemente, con esto Flores mostraba que su compromiso con un nuevo gobiemo (con una "Nueva Alianza", con un "Nuevo ARENA") no era palabrería preeleccionaria, sino más bien una promesa real. Tan real que habría obligado a Cristiani - la permanente conciencia arenera del inquieto Flores- a aclarar que las figuras que integrarían el gabinete deberían ser "muy cercanas" al partido. Y es que la preocupación que externó el presidente del COENA no era vana: Flores prometía cambiar los fundamentos con los que hasta entonces se elegía al gabinete: a dedo y restringiendo la elección a personalidades totalmente plegadas a los dictámenes e ideología del partido.

Desde el optimismo y haciendo a un lado la astucia política que hay que reconocer en ARENA, la medida que pretende implementar Flores sería signo de que se está a las puertas de un cambio en la forma en que se han conducido los gobiernos areneros. Por primera vez en diez años, un presidente electo ha mostrado voluntad en darle continuidad a al menos una de sus promesas electorales. Siendo en este caso una tan importante co- a Flores para atraer (y ampliar) las simpatías del electorado. En este sentido, qué más eficaz que montar un escenario en el cual el político de avanzada entra en contradicciones con figuras de la vieja guardia, las cuales al final terminan cediendo a los bien intencionados ideales del primero.

Desde esta interpretación, la gestión que realice Flores desde el momento que tome posesión hasta cuando se den los resultados de las elecciones legislativas y municipales será el telón de fondo de la campaña electoral arenera. Un telón de fondo con el que se pretendería remozar a una clase política tan fiel a su herencia ideológica como a su radical pragmatismo. De ser así, cabe esperar más sorpresas de Francisco Flores y de ARENA a lo largo del período comprendido entre la actual coyuntura y marzo del 2000.

Ahora bien, que lo anterior sea cierto no hace que la decisión de Flores de conformar un gabinete de gobierno diferente deje de ser una oportunidad importante para la sociedad civil e incluso para el resto de partidos políticos. Una buena forma de sacarle provecho a la dinámica por la que atraviesa ARENA sería tomarle la palabra a Francisco Flores. Es decir, las organizaciones sociales, independientemente de su tendencia ideológica, deberían de proponer sus candidatos al gabinete y vigilar que el proceso de elección sea realmente abierto y limpio.

La posibilidad que ha abierto Flores $\longrightarrow$ la voluntad de poder de ARENA - se desperdiciaría si la incredulidad o el adormecimiento de los partidos de la oposición, de las universidades y de los gremios de profesionales hicieran que éstos no atendieran al llamado y dejaran el control total del 
gobierno en manos de ARENA por ausencia de contrincantes. Lo importante de esta coyuntura es aprovechar y radicalizar el talante democrático con el que Flores está pretendiendo iniciar su presidencia. Con ello se le obligaría al Presidente electo a realmente llevar a cabo lo que ha prometido al respecto o a desmentirse públicamente sobre algo que en ningún momento quiso $\longrightarrow$ pudo- cumplir.

Sin embargo, hasta la fecha, la respuesta de la sociedad civil ante la coyuntura que ha abierto Flores no es alentadora. Por un lado, los grandes medios de comunicación, en especial la prensa escrita, se han lanzado a la tarea de alabar sin cortapisas a Flores y su proceso de elección del gabinete, dejando de lado abordar críticamente el absoluto hermetismo y sigilo con el que se están dando las discusiones. Aunque este hermetismo podría estar siendo utilizado por Flores como una forma de protegerse de la injerencia de su propio partido, los medios se han conformado con ocupar el pequeñísimo espacio que les ha asignado el Presidente electo en el proceso, aun cuando ello les ha implicado hacer promesa de silencio y total confidencialidad sobre el rumbo de las discusiones en la mesa de elección del gabinete.

Así pues, la supuesta apertura del proceso se ha limitado a que los medios describan los pormenores más accesorios de la elección del gabinete (quién habla primero en las reuniones, cuál es el orden y las reglas de la participación, qué personaje es el más ocurrente y gracioso), pero no así su sustancia: los nombres de los candidatos, la índole o el origen de las presiones para la elección de uno $\mathbf{u}$ otro, las fuerzas sociales que estarían participando en el proceso, los requisitos concretos que se están exigiendo para entrar a la nómina de elegibles, etc. Flores ha mostrado el decorado, la utilería y el nombre de los directores de la obra, pero ha sido completamente reacio (en esto es muy arenero) a que la sociedad conozca los diálogos y la trama del proceso que está dirigiendo. En este sentido, que Flores haya ubicado el proceso de elección del gabinete fuera de las instalaciones de su partido y que en la mesa de negociaciones no se observen elementos de la parafernalia arenera es completamente intrascendente e inocuo.

Por otro lado, la mayoría de las fuerzas sociales del país, en este contexto de absoluta desinformación, han dado su voto de confianza y respaldo al proceso de Flores. Tanto la gran empresa como algunos partidos de oposición se han expresado benignamente frente a una realidad de la que nadie, al parecer, conoce nada. Esto, obviamente, además de irresponsable es peligroso. Primero, porque con ello se avala un proceso del que, tal como están marchando las cosas, se conocerán los resultados hasta que ya no exista posibilidad de cambio o refutación. Y segundo, porque se está perdiendo de vista que los alcances más importantes de la propuesta de Flores residen en la apertura y la transparencia que en teoría rodearían al proceso de principio a fin, y no en que, por ejemplo, David Escobar Galindo (el comodín de las administraciones areneras) participe en la elección de los futuros ministros o en que Flores declare que sólo en él recaerá la decisión final sobre los candidatos.

Llegados hasta esta temática, es posible extraer dos conclusiones: (a) Si bien Flores ha dado signos importantes de que abanderará una forma de hacer política nunca antes vista en el interior de ARENA, ello aún no da pie para afirmar que se está a las puertas de una radical transformación del partido en el poder. Ni Flores es toda la derecha ni puede ser visto como la punta visible de un sector arenero consolidado y significativo con ideas nuevas. En muchos sentidos, el Presidente electo está solo y quiere mantenerse en este estado. Muy posiblemente ARENA lo está dejando hacer para aprovechar una coyuntura política que exige caras y actitudes nuevas. La burbuja que ha creado Flores para mantenerse aislado podría interpretarse, desde este punto de vista, como una forma de tomar ventaja de la voluntad de poder de su partido y operar con la autonomía que necesitaría para hacer operar cambios importantes. Si el partido estuviera cambiando o si Flores fuera miembro de una nueva camada de areneros, sería difícil explicar porqué no hay miembros jóvenes del partido en las comisiones que ha formado y porqué le ha sido necesario aislarse de toda forma de contaminación externa.

(b) Ante un proceso de elección de gabinete que en buen grado se ha apartado de lo que en un principio se anunció (por ejemplo, aún no se sabe si de la sociedad civil han emanado nombres de candidatos para los ministerios, no se ha verificado que en la contienda estén participando figuras ajenas a ARENA y se ha vedado completamente el acceso de la prensa a cualesquiera de las fases del proceso), la mayoría de los actores sociales, conformándose con lo superficial, lo han calificado como la manifestación por excelencia del talante renovador de Francisco Flores y de su nuevo 
gobiemo. Con ello han obviado asumir el papel vigilante y fiscalizador que les correspondía - y que incluso Flores les asignó en sus discursos- en el proceso de elección del gabinete. Amparado en su hermetismo y la lejanía de la sociedad civil, Flores parece estar haciendo las cosas sin mayor guía que su propio arbitrio.

Henry Marcel Vargas Escolero 